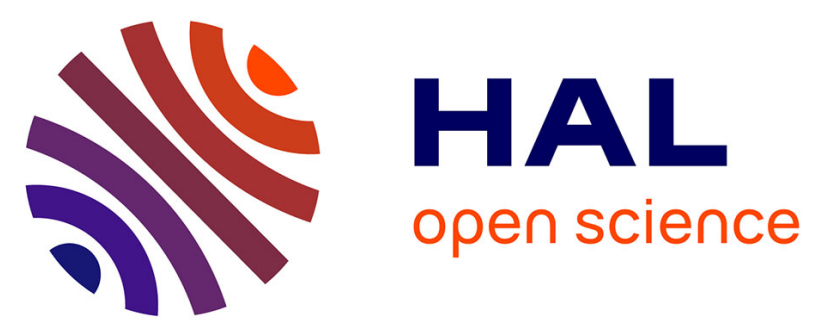

\title{
The impact of preoperative breast MRI on the re-excision rate in invasive lobular carcinoma of the breast
}

\author{
R. M. Mann, C. E. Loo, T. Wobbes, P. Bult, J. O. Barentsz, K. G. A.
} Gilhuijs, C. Boetes

\section{To cite this version:}

R. M. Mann, C. E. Loo, T. Wobbes, P. Bult, J. O. Barentsz, et al.. The impact of preoperative breast MRI on the re-excision rate in invasive lobular carcinoma of the breast. Breast Cancer Research and Treatment, 2009, 119 (2), pp.415-422. 10.1007/s10549-009-0616-6 . hal-00535411

\section{HAL Id: hal-00535411 \\ https://hal.science/hal-00535411}

Submitted on 11 Nov 2010

HAL is a multi-disciplinary open access archive for the deposit and dissemination of scientific research documents, whether they are published or not. The documents may come from teaching and research institutions in France or abroad, or from public or private research centers.
L'archive ouverte pluridisciplinaire HAL, est destinée au dépôt et à la diffusion de documents scientifiques de niveau recherche, publiés ou non, émanant des établissements d'enseignement et de recherche français ou étrangers, des laboratoires publics ou privés. 


\title{
The impact of preoperative breast MRI on the re-excision rate in invasive lobular carcinoma of the breast
}

\author{
R. M. Mann - C. E. Loo • \\ T. Wobbes $\cdot$ P. Bult $\cdot$ J. O. Barentsz $\cdot$ \\ K. G. A. Gilhuijs $\cdot$ C. Boetes
}

Received: 26 September 2009/Accepted: 21 October 2009/Published online: 3 November 2009

(C) Springer Science+Business Media, LLC. 2009

\begin{abstract}
Re-excision rates after breast conserving surgery (BCS) of invasive lobular carcinoma (ILC) are high. Preoperative breast MRI has the potential to reduce re-excision rates, but may lead to an increased rate of mastectomies. Hence, we assessed the influence of preoperative breast MRI on the re-excision rate and the rate of mastectomies. We performed a retrospective cohort study of a consecutive series of patients with ILC who presented in one of two dedicated tertiary cancer centers between 1993 and 2005. We assessed the initial type of surgery (BCS or mastectomy), the re-excision rate and the final type of surgery. Patients were stratified into two groups:
\end{abstract}

R. M. Mann $(\bowtie) \cdot$ J. O. Barentsz $\cdot$ C. Boetes

Department of Radiology, Radboud University Nijmegen

Medical Centre, huispost 667, Geert Grooteplein 10,

P.O. Box 9101, 6500 HB Nijmegen, The Netherlands

e-mail: r.mann@rad.umcn.nl

C. E. Loo · K. G. A. Gilhuijs

Department of Radiology, The Netherlands Cancer Institute/

Antoni van Leeuwenhoek Hospital, Amsterdam,

The Netherlands

T. Wobbes

Department of Surgery, Radboud University Nijmegen Medical

Centre, Nijmegen, The Netherlands

P. Bult

Department of Pathology, Radboud University Nijmegen

Medical Centre, Nijmegen, The Netherlands

C. Boetes

Department of Radiology, Maastricht University Medical

Center, Maastricht, The Netherlands

C. Boetes

GROW, School for Oncology and Developmental Biology,

Maastricht University Medical Center, Maastricht,

The Netherlands those who received preoperative MRI (MR+ group) and those who did not (MR - group). In the MR - group, 27\% of the patients underwent a re-excision after initial BCS. In the MR+ group, this rate was significantly lower at $9 \%$. The odds ratio was 3.64 (95\% CI: $1.30-10.20, P=0.010$ ). There was a trend towards a lower final mastectomy rate in the $\mathrm{MR}+$ group compared to the MR - group (48 vs. 59\%, $P=0.098)$. In conclusion, preoperative MRI in patients with ILC can reduce re-excision rates without increasing the rate of mastectomies.

Keywords Breast cancer - Breast MRI - Breast conserving surgery $\cdot$ Mastectomy $\cdot$ Invasive lobular carcinoma $\cdot$ Re-excision rate

\section{Introduction}

Invasive lobular carcinoma of the breast (ILC) is more prone to incomplete surgical excision and subsequent re-excision than other histological types of breast cancer. Reported re-excision rates in ILC after breast conserving surgery (BCS) range from 29 to $67 \%$ [1-5]. In 16-48\% of patients with ILC local surgical therapy is still converted to mastectomy after failure of BCS [1, 5-10].

Contrast-enhanced magnetic resonance imaging (MRI) of the breast has often been proposed as the solution to failure of obtaining tumor free margins in BCS and subsequent re-excision or conversion to mastectomy. The technique is superior to conventional imaging methods in staging ILC [11-18], which is mainly achieved by improving tumor delineation and detection of additional tumor foci.

Conversely, many studies have shown that preoperative breast MRI changes therapy in $12-33 \%$ of patients from 
BCS to mastectomy $[11,13,16,19-22]$. Although the changes may be appropriate in $88 \%$ of cases according to pathology [23], this percentage is still relatively high compared to local recurrence rates [24]. Nonetheless, large trials have demonstrated that incomplete tumor excision is a risk factor for local recurrence [25]. Hence, the question remains whether MRI is capable of reducing the frequency of incomplete surgery and subsequent need for re-excisions without adverse side effects, such as dramatically increasing the rate of mastectomies [26-28]. This information is essential if MRI is to be implemented in the standard preoperative staging of all patients with ILC.

The aim of this study, therefore, was to assess whether preoperative breast MRI influences the rate of re-excisions and the rate of mastectomies in a large consecutive series of patients with ILC.

\section{Materials and methods}

\section{Ethics}

This cohort study was performed according to good clinical practice and the Dutch legal regulations. No approval of the local ethical committees or informed consent was needed for this study. However, patients who participated in earlier prospective clinical trials (approved by the local ethical committees) tailored to different research questions provided informed consent for those studies.

\section{Patients}

The pathological and oncological databases of the Radboud University Nijmegen Medical Centre (RUNMC) and the Netherlands Cancer Institute/Antoni van Leeuwenhoek Hospital (NKI-AVL) were searched and all patients who presented with ILC between January 1993 and December 2005 at the RUNMC and between January 1999 and December 2005 at the NKI-AVL were included. Both hospitals perform preoperative breast MRI in nearly all patients with ILC since early 2006. Consequently, no patients were included after 2005.

We excluded all patients who: (1) had a history of cancer of any type $(n=32)$, (2) had prior surgery to the affected breast except for excisional biopsy to establish the diagnosis $(n=15)$, (3) were initially treated with neoadjuvant chemotherapy or other non-surgical techniques $(n=41)$, (4) were initially treated in another hospital $(n=378)$.

\section{Data acquisition}

We reviewed the medical, radiological, and pathological records of all patients who met the inclusion criteria. We registered patient characteristics, when the diagnosis was established, time to initial surgery, and type of initial surgery (BCS or mastectomy) [29]. Furthermore, the number and type of repeat operations after initial surgery (due to the detection of involved resection margins at pathological examination in more than two low power fields $(10 \times$ objective) at microscopy) were recorded. When tumor margins were clear or were only focally involved at microscopy (less than two low power fields) and no reexcision was deemed necessary, the surgical procedure was recorded as being radical (final pathology).

The radiological databases were searched for imaging studies to establish: (1) the type of conventional imaging performed to detect and stage the tumor, (2) whether contrast enhanced breast MRI was performed within 3 months prior to initial surgery, (3) the number of days between tumor detection (either at mammography or clinically), the breast MRI, and final pathology. All patients in whom breast MRI was performed were assumed to have been preoperatively staged with breast MRI.

The pathology databases were reviewed to obtain tumor size and pathological characteristics from the surgical specimens at final pathology. In the case of multifocal lesions the largest diameter of the total area with tumor foci was recorded. If this information was not available, the size of the largest focus was recorded.

\section{Breast MRI}

Due to the extensive study period and data acquisition in two cancer centers, the patients were scanned using various MRI systems, various field strengths ranging from 1.0 to $3.0 \mathrm{~T}$ and various scan protocols. The spatial resolution of these protocols generally improved over time. However, all patients were scanned in the prone position with the use of a dedicated bilateral breast coil. All protocols included a series of $\mathrm{T} 1$ weighted sequences that was repeated at least four times, first prior to the administration of a Gd-containing contrast agent and then several times after intravenous contrast administration at a dose of $0.1 \mathrm{mmol} / \mathrm{kg}$. In all patients, subtraction images were created from the pre and post contrast scans to evaluate tumor morphology and tumor kinetics (internal enhancement and enhancement curve type) according to the BIRADS lexicon [30]. The size of the tumor was measured and reported in three perpendicular planes (coronal, axial, and sagital). The indications for the performance of MRI were diverse and included accepted clinical indications, patient wish and participation in clinical studies that assessed: (1) the radiologic pathologic correlation of MR-visible tumors, (2) screening of women at high life-time risk of breast cancer, (3) preoperative staging, and (4) new MRI sequences. 
Therapeutic approach

Prior to surgery, the available information for each patient (including clinical examination, mammography in two directions, ultrasound of the affected breast, and breast MRI when available) was discussed in a multidisciplinary meeting of breast cancer specialists (radiologists, pathologists, surgeons, radiation oncologists, and medical oncologists). This team devised the treatment plan in consensus.

Both hospitals applied the policy that MRI findings required pathologic proof of malignancy prior to adaptation of the surgical plan, except if such adaptation was a small extension of a local excision. Proof of malignancy was typically acquired by second look ultrasound or MRI guided (excision) biopsy [29, 31].

\section{Statistics}

Our primary endpoint was to compare the rate of re-excisions in all patients who underwent preoperative MRI compared with the rate of re-excisions in those who did not undergo preoperative MRI. The rate of initial mastectomies in both groups, the final rate of mastectomies and the time between tumor detection and final pathology were regarded as secondary endpoints.

In addition, we analyzed the rate of re-excisions and the final mastectomy rate in the subset of patients that underwent initial BCS.

All means are expressed as mean \pm 1 SD. Binomial comparisons were performed using the chi-square test to check for statistical significance, or a Fisher's exact test whenever appropriate. Continuous variables were compared with the $T$-test for independent samples. Correlations were assessed with Pearson's correlation coefficient. We calculated odds ratios and $95 \%$ confidence intervals for the chance of re-excision with and without preoperative breast MRI for the whole population and for the subset of patients that initially underwent BCS. Calculations were performed using SPSS version 16.0 (SPSS Inc. Chicago, USA). $P$ values smaller than 0.05 were considered significant.

\section{Results}

Patient and tumor characteristics

In total, 267 patients met the inclusion criteria. Ninety-nine of these women underwent pre-operative MRI (MR+ group), 168 did not (MR - group). Patient groups were comparable, although the mean age of patients in the MR+ group was less. Patient characteristics are described in Table 1.
Table 1 Characteristics of the patients included in the study

\begin{tabular}{llll}
\hline & $\begin{array}{l}\text { MR }- \\
(N=168)\end{array}$ & $\begin{array}{l}\text { MR+ } \\
(N=99)\end{array}$ & $P$ value \\
\hline Age (years) & $61 \pm 13$ & $56 \pm 10$ & 0.001 \\
Mean & 60 & 57 & \\
Median & $37-89$ & $36-86$ & \\
Range & & & \\
Menopausal state & $51(30)$ & $30(30)$ & 0.880 \\
Premenopausal & $106(63)$ & $64(65)$ & \\
Postmenopausal & $11(7)$ & $5(5)$ & \\
HRT & & & \\
Family history & $137(82)$ & $80(81)$ & 0.578 \\
Blank & $31(18)$ & $18(18)$ & \\
Positive & $0(0)$ & $1(1)$ & \\
BRCA mutation carrier & & & \\
\hline
\end{tabular}

Numbers between parenthesis represent percentages

$H R T$ complete hormone replacement therapy

The tumors in both groups were equally distributed in size and although the rate of multifocal lesions in the MR+ group was slightly higher, this did not reach statistical significance. Concurrent DCIS was incidentally present in both groups, whereas concurrent LCIS was very common and often extensive. We did not observe any significant difference in hormone receptor expression. Although the Her2/Neu receptor was more often over-expressed in the MR - group, the expression was only assessed in 155 patients and the difference did not reach statistical significance. In Table 2 tumor characteristics are shown.

\section{Surgery}

Initial surgery was radical in 237 of 267 (89\%) patients. In total, 30 patients underwent re-excision because of involved margins. Only one of these patients underwent initial mastectomy. This patient underwent an additional resection of residual tumor in the axillary tail. In 4 patients, the reexcision consisted of an extended local excision, in 25 cases the surgical procedure was secondary mastectomy.

The rate of re-excisions was significantly higher in the MR - group (15\%) than in the $\mathrm{MR}+$ group $(5 \%)$ $(P=0.014)$, as is shown in Table 3 . The odds ratio for reexcision was 3.29 (95\% CI 1.22-8.85). In other words, patients in the MR - group were 3.3 times more likely to undergo re-excision than patients in the $\mathrm{MR}+$ group.

Initial mastectomy was performed in 122 of 267 patients $(46 \%)$. We did not observe a higher rate of mastectomies in the MR+ group. The final rate of mastectomies was even lower in the MR+ group, though this did not reach statistical significance. Overall, the rate of initial mastectomies declined over the years. We observed a negative 
Table 2 Pathological characteristics of the included malignancies

\begin{tabular}{|c|c|c|c|}
\hline & $\mathrm{MR}-(N=168)$ & $\mathrm{MR}+(N=99)$ & $P$ value \\
\hline \multicolumn{4}{|l|}{ Size $(\mathrm{cm})$} \\
\hline Mean & $3.4 \pm 2.8$ & $3.4 \pm 2.6$ & 0.985 \\
\hline Median & 2.3 & 2.4 & \\
\hline Range & $0.1-14.0$ & $0.2-11.0$ & \\
\hline \multicolumn{4}{|l|}{ Focality } \\
\hline Unifocal & $80(48)$ & $44(44)$ & 0.615 \\
\hline Multifocal & $88(52)$ & $55(56)$ & \\
\hline \multicolumn{4}{|l|}{ DCIS present } \\
\hline No & $128(76)$ & $74(75)$ & 0.849 \\
\hline Limited & $28(17)$ & $17(17)$ & \\
\hline Extensive & $9(5)$ & $7(7)$ & \\
\hline \multicolumn{4}{|l|}{ LCIS present } \\
\hline No & $31(18)$ & 19 (19) & 0.994 \\
\hline Limited & $57(34)$ & $34(34)$ & \\
\hline Extensive & $78(46)$ & $46(46)$ & \\
\hline \multicolumn{4}{|c|}{ Estrogen receptor expression } \\
\hline Negative & $5(3)$ & $2(2)$ & 0.720 \\
\hline Positive & $144(86)$ & $83(84)$ & \\
\hline Missing & $19(11)$ & $14(14)$ & \\
\hline \multicolumn{4}{|c|}{ Progesterone receptor expression } \\
\hline Negative & $36(21)$ & $17(17)$ & 0.460 \\
\hline Positive & $111(66)$ & $67(68)$ & \\
\hline Missing & $21(13)$ & $15(15)$ & \\
\hline \multicolumn{4}{|c|}{ Her2/Neu expression } \\
\hline Normal & $88(52)$ & $55(56)$ & 0.057 \\
\hline Over expressed & $11(7)$ & $1(1)$ & \\
\hline Missing & $69(41)$ & $43(43)$ & \\
\hline
\end{tabular}

Numbers between parenthesis represent percentages

DCIS ductal carcinoma in situ, LCIS lobular carcinoma in situ

Table 3 Rate of re-excisions and mastectomies in the entire study population

\begin{tabular}{llcl}
\hline & $\mathrm{MR}-(N=168)$ & $\mathrm{MR}+(N=99)$ & $P$ value \\
\hline Re-excisions & $25(15)$ & $5(5)$ & 0.014 \\
Initial mastectomies & $78(46)$ & $44(45)$ & 0.753 \\
Final mastectomies & $99(59)$ & $48(48)$ & 0.098 \\
\hline
\end{tabular}

Numbers between parenthesis represent percentages

correlation coefficient of $-0.19(P=0.002)$ between the year of treatment and the rate of initial mastectomies (Fig. 1).

Patients initially treated with breast conserving surgery

In the subset of patients who initially underwent BCS after preoperative staging, mean tumor size was lower and multifocality was less common. We did not observe differences in tumor size or rate of multifocality between the
MR - and MR+ groups (Table 4). However, the rate of reexcisions was significantly higher in patients in the MRgroup, than in patients in the MR+ group (odds ratio 3.64 (95\% CI 1.30-10.20)). Consequently, mastectomy as final therapy was much more common in patients who initially underwent BCS but did not undergo preoperative breast MRI $(P=0.010)$.

We did not observe differences in tumor characteristics of initially incompletely excised tumors in the two groups. Mean tumor size was $3 \mathrm{~cm}$ in both groups, ranging from 0.8 to $7.0 \mathrm{~cm}$ in the MR - group, and from 1.0 to $7.6 \mathrm{~cm}$ in the MR+ group $(P=0.959)$. In the MR - group 17 of 25 tumors $(68 \%)$ were multifocal, while 3 of 5 tumors $(60 \%)$ in the MR+ group were multifocal $(P=1.000)$.

Time

The mean time from diagnosis to breast MRI in the MR+ group was $14( \pm 11)$ days, ranging from 0 (tumor detected at MRI) to 53 days. The mean time from diagnosis to final pathology in patients in whom initial surgery was successful for $40( \pm 22)$ days in the MR - group and $38( \pm 18)$ days in the MR+ group $(P=0.436)$. Hence, no evidence could be found that the time to final pathology was increased by the preoperative MRI.

However, failure to perform radical surgery increased the time to final pathology to $67( \pm 48)$ days in the MRgroup $(P=0.010)$ and $81( \pm 42)$ in the $\mathrm{MR}+$ group $(P=0.078)$, respectively.

Overall this led to a slightly longer time to final pathology in the MR - group of $44( \pm 29)$ days compared to $40( \pm 21)$ days in the MR+ group, although this did not reach statistical significance $(P=0.238)$.

\section{Discussion}

The most essential finding of our study is that preoperative breast MRI in patients with ILC who undergo BCS reduced the rate of surgical re-excision after BCS.

Furthermore, preoperative MRI was not associated with an increased rate of initial mastectomies, the most common objection to preoperative staging of breast cancer with breast MRI. In fact, the final rate of mastectomies was higher in patients who did not have a preoperative breast MRI. Hence, this is the first study that, in terms of outcome, shows benefit of preoperative breast MRI in patients with ILC.

With conventional methods (mammography and ultrasound) adequate staging of ILC is difficult [10, 32-34]. The sensitivity is limited and although most lobular carcinomas do eventually present as a mass, ILC is often much larger than anticipated and is often multifocal $[10,35]$. 
Fig. 1 Rate of patients initially treated with mastectomy by year of inclusion

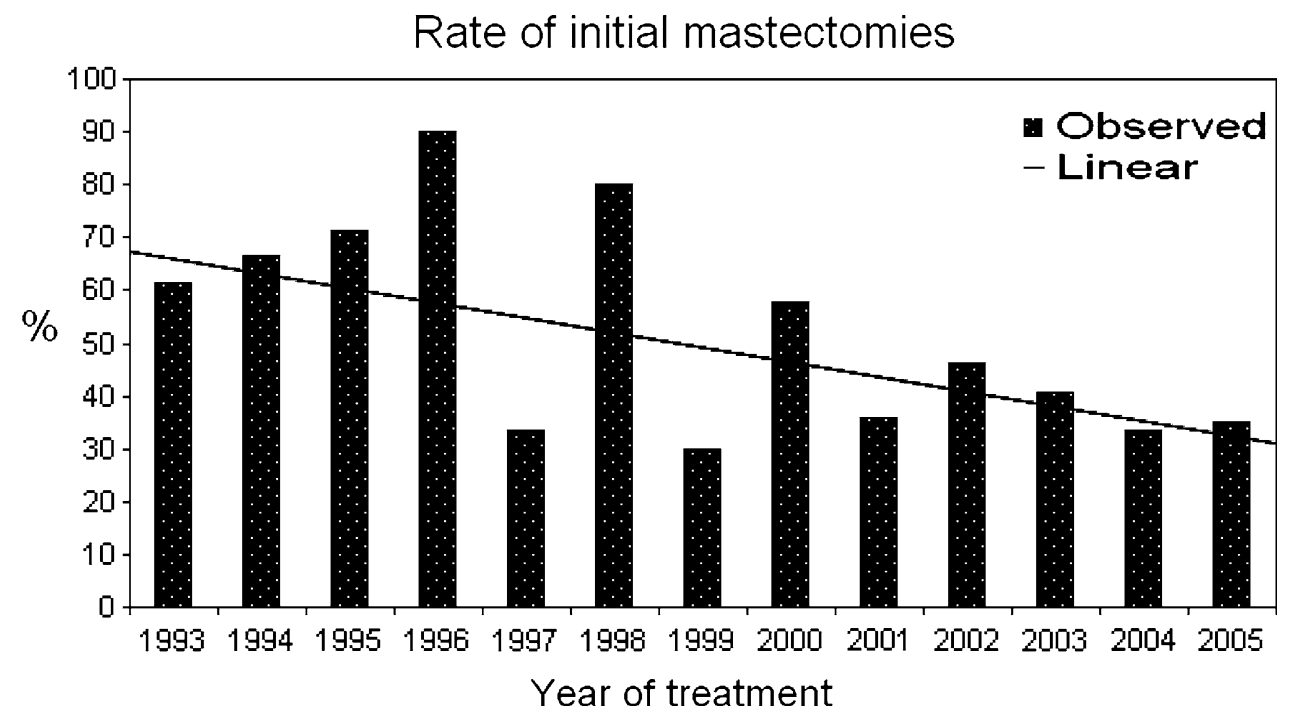

Table 4 Results in the subset of patients that initially underwent BCS

\begin{tabular}{llll}
\hline & MRI- & MRI + & $P$ value \\
\hline$N$ & 90 & 55 & \\
Mean tumor size (cm) & $2.1 \pm 1.4$ & $2.0 \pm 1.4$ & 0.724 \\
Multifocal & $37(41)$ & $19(34)$ & 0.431 \\
Re-excisions & $24(27)$ & $5(9)$ & 0.010 \\
Final mastectomies & $21(23)$ & $4(7)$ & 0.013 \\
\hline
\end{tabular}

Numbers between parenthesis represent percentages

MRI has proved to tackle many of the difficulties in detection and staging that occur with conventional modalities. With a stable sensitivity of approximately $93 \%$, an accuracy in lesion size estimation of $80 \%$ (with an accompanying $10 \%$ underestimation of lesion size and $10 \%$ overestimation of lesion size) and a good correlation with tumor size at pathology, breast MRI aids in lesion appreciation [11, 14, 20, 23]. Consequently, MRI has been shown to change the therapeutic approach in approximately one-third of patients with ILC [11, 16, 19, 21-23].

Nevertheless, even in ILC, preoperative breast MRI is still disputed, because breast cancer staging with MRI is thought to delay treatment and to result in more aggressive surgery $[9,28,29]$. Additional lesions detected by breast MRI raise the need for additional work-up.

Since we did not observe a difference in time to final pathology between the MR - group and the MR+ group, it is apparently feasible to perform additional work-up within 40 days on average (the mean time between diagnosis and final pathology in the present study). As long as the waiting time for surgery is longer, preoperative breast MRI will not delay therapy. Re-excision does, however, delay therapy.

The reduction in the re-excision rate is considered to be emotionally important to patients, as it prevents the anxiety that is caused by a second surgical procedure and the increased time to full excision. Moreover, it has been shown that a good cosmetic outcome is reduced by reexcision [36, 37]. Finally, re-excision is associated with significant financial costs, which may be reduced by preoperative MRI. However, this requires further study.

In a recent study by Pengel et al. [38], a similar reduced rate of re-excisions due to preoperative breast MRI was shown in a subgroup of patients with IDC. A reduction in the re-excision rate in ILC was not observed but far fewer patients with ILC were included and both focal and extensive involvement of resection margins were regarded as unsuccessful surgery. Moreover, they did not analyse the impact of pre-operative breast MRI on the initial mastectomy rate.

Because studies have shown that the rate of local recurrences is higher in patients who undergo re-excisions than in patients who are initially successfully treated [39, 40], our study suggests that preoperative MRI in patients with ILC has the potential to improve local control and therefore survival. However, this negative effect from reexcisions was not evident from other studies [2], and is therefore uncertain.

So far, only two studies have evaluated the impact of preoperative breast MRI on recurrence and survival, none of which evaluated specifically ILC. Unfortunately these studies had contradictory results.

Fischer et al. [41] showed a reduced rate of local recurrences after preoperative MRI, but this study is largely biased due to very different tumor stages between groups. More recently Solin et al. [42] did not observe any differences in local control between patients that did or did not undergo pre-operative MRI. However, they had only a short follow-up period and included many patients in the $\mathrm{MR}+$ group that underwent MRI only after initial surgery. 
We agree that the most valid proof of improved outcome is a clear reduction in breast cancer mortality, following a reduction of local recurrence. Such evidence in patients with ILC is still lacking, we neither assessed local recurrence nor survival in this study. However, due to improving overall diagnosis and treatment current recurrence rates have dropped to approximately $0.6-1 \%$ per year [43]. Furthermore, ILC is a relatively infrequent breast cancer, so large studies to evaluate the impact of preoperative MRI on recurrence and survival will be acquired over a very long time span. Consequently, surgical approaches and adjuvant therapies will have continued to develop and an effect on outcome using these terms may be difficult to interpret as they are prone to bias.

There are several limitations to our study.

First, the non-randomized and retrospective nature of this study must be taken into account. However, since both the American College of Radiology (ACR) and the European society of breast imaging (Eusobi) currently recommend pre-operative breast MRI for evaluation of the contralateral breast in all women with proven breast cancer $[44,45]$, prospective randomized studies on patients with breast cancer can no longer be deemed ethical.

Second, although mastectomy is more commonly performed for ILC than for IDC due to the typically larger extension of ILC and preference of surgeons and patients, we still observed relatively high rates of initial mastectomies in both groups. This is probably mainly explained by the long time span of the study, since we observed a clear decline of the rate of initial mastectomies over time. The initial mastectomy rate of $35 \%$ observed in 2005 is comparable to reported values in literature $[6,9]$.

Third, from the observed similarity in the rates of initial mastectomy between groups it is likely that a selection bias has occurred. Many studies have shown that preoperative MRI changes the surgical approach in $22-44 \%$ of patients [11-18], and as mentioned before, in $12-33 \%$ of patients this change is a conversion from BCS to mastectomy [11, $13,16,19-22]$. Based on few reported findings, this rate of therapy change is balanced by a conversion rate in the opposite direction of approximately 5\% [11]. Consequently, a $15-20 \%$ higher initial mastectomy rate in the $\mathrm{MR}+$ group would be expected. Since tumor sizes were not different between groups, nor was the rate of multifocality, patients who were unlikely to undergo BCS based on psychological factors, were apparently also less likely to undergo preoperative MRI. We believe this also explains the slight age difference between groups that is also observed in other studies [38, 42].

Fourth, all patients were treated in tertiary dedicated cancer centers, generally treating larger and more technically challenging carcinomas. Both centers also had a wide experience in the use of breast MRI which may have improved the outcomes of this study. Since breast MRI is subject to a learning curve for both radiologists and surgeons, our results cannot be directly extrapolated to centers without extensive experience.

Last, breast MRI has also evolved over time. Consequently, the MRI protocols were non-uniform in the study period. Moreover, nowadays spatial resolutions are achievable that were impossible only 5 years ago. Furthermore, the addition of other sequences, such as $\mathrm{T} 2$ and diffusion weighted imaging, may further improve preoperative staging. Our study only evaluated the use of contrast enhanced breast MRI. It is therefore impossible to tell whether or not such advantages may result in further benefit for patients [46, 47].

Since we only evaluated ILC, it is not possible to extrapolate our findings to other types of breast cancer. However, we need to discuss the role of preoperative breast MRI in patients who do not qualify for BCS. The main objection that preoperative breast MRI will increase the chance of mastectomy obviously does not hold. Conversely, there is a small chance that preoperative breast MRI will result in BCS due to better delineation of the tumor [11]. Moreover, the indication for screening of the contralateral breast remains valid regardless of the size of the ipsilateral tumor $[44,45]$. Thus, for optimal therapy and optimal performance of preoperative MRI, it is recommended in all patients with ILC, not only the subset that is eligible for BCS.

In summary, preoperative breast MRI in patients with ILC leads to a reduction of the re-excision rate without increasing the rate of initial mastectomies and is thus directly beneficial for patients with ILC.

\section{References}

1. Keskek M, Kothari M, Ardehali B, Betambeau N, Nasiri N, Gui GP (2004) Factors predisposing to cavity margin positivity following conservation surgery for breast cancer. Eur J Surg Oncol 30(10): 1058-1064

2. O'Sullivan MJ, Li T, Freedman G, Morrow M (2007) The effect of multiple reexcisions on the risk of local recurrence after breast conserving surgery. Ann Surg Oncol 14(11):3133-3140

3. Smitt MC, Horst K (2007) Association of clinical and pathologic variables with lumpectomy surgical margin status after preoperative diagnosis or excisional biopsy of invasive breast cancer. Ann Surg Oncol 14(3):1040-1044

4. van den Broek N, van der Sangen MJ, van de Poll-Franse LV, van Beek MW, Nieuwenhuijzen GA, Voogd AC (2007) Margin status and the risk of local recurrence after breast-conserving treatment of lobular breast cancer. Breast Cancer Res Treat 105(1):63-68

5. Waljee JF, Hu ES, Newman LA, Alderman AK (2008) Predictors of re-excision among women undergoing breast-conserving surgery for cancer. Ann Surg Oncol 15(5):1297-1303

6. Dillon MF, Hill AD, Fleming FJ, O'Doherty A, Quinn CM, McDermott EW, O’Higgins N (2006) Identifying patients at risk 
of compromised margins following breast conservation for lobular carcinoma. Am J Surg 191(2):201-205

7. Hussien M, Lioe TF, Finnegan J, Spence RA (2003) Surgical treatment for invasive lobular carcinoma of the breast. Breast 12(1):23-35

8. Molland JG, Donnellan M, Janu NC, Carmalt HL, Kennedy CW, Gillett DJ (2004) Infiltrating lobular carcinoma-a comparison of diagnosis, management and outcome with infiltrating duct carcinoma. Breast 13(5):389-396

9. Morrow M, Keeney K, Scholtens D, Wei J, Steel J, Khan SA (2006) Selecting patients for breast-conserving therapy: the importance of lobular histology. Cancer 106(12):2563-2568

10. Yeatman TJ, Cantor AB, Smith TJ, Smith SK, Reintgen DS, Miller MS, Ku NN, Baekey PA, Cox CE (1995) Tumor biology of infiltrating lobular carcinoma. Implications for management. Ann Surg 222(4):549-559

11. Caramella T, Chapellier C, Ettore F, Raoust I, Chamorey E, BaluMaestro C (2007) Value of MRI in the surgical planning of invasive lobular breast carcinoma: a prospective and a retrospective study of 57 cases: comparison with physical examination, conventional imaging, and histology. Clin Imaging 31(3):155-161

12. Kepple J, Layeeque R, Klimberg VS, Harms S, Siegel E, Korourian S, Gusmano F, Henry-Tillman RS (2005) Correlation of magnetic resonance imaging and pathologic size of infiltrating lobular carcinoma of the breast. Am J Surg 190(4):623-627

13. Kneeshaw PJ, Turnbull LW, Smith A, Drew PJ (2003) Dynamic contrast enhanced magnetic resonance imaging aids the surgical management of invasive lobular breast cancer. Eur J Surg Oncol 29(1):32-37

14. Mann RM, Veltman J, Barentsz JO, Wobbes T, Blickman JG, Boetes C (2008) The value of MRI compared to mammography in the assessment of tumour extent in invasive lobular carcinoma of the breast. Eur J Surg Oncol 34(2):135-142

15. Qayyum A, Birdwell RL, Daniel BL, Nowels KW, Jeffrey SS, Agoston TA, Herfkens RJ (2002) MR imaging features of infiltrating lobular carcinoma of the breast: histopathologic correlation. AJR Am J Roentgenol 178(5):1227-1232

16. Rodenko GN, Harms SE, Pruneda JM, Farrell RS Jr, Evans WP, Copit DS, Krakos PA, Flamig DP (1996) MR imaging in the management before surgery of lobular carcinoma of the breast: correlation with pathology. AJR Am J Roentgenol 167(6):14151419

17. Schelfout K, Van Goethem M, Kersschot E, Verslegers I, Biltjes I, Leyman P, Colpaert C, Thienpont L, Van Den HJ, Gillardin JP, Tjalma W, Buytaert P, De SA (2004) Preoperative breast MRI in patients with invasive lobular breast cancer. Eur Radiol 14(7):1209-1216

18. Weinstein SP, Orel SG, Heller R, Reynolds C, Czerniecki B, Solin LJ, Schnall M (2001) MR imaging of the breast in patients with invasive lobular carcinoma. AJR Am J Roentgenol 176(2):399-406

19. Bedrosian I, Mick R, Orel SG, Schnall M, Reynolds C, Spitz FR, Callans LS, Buzby GP, Rosato EF, Fraker DL, Czerniecki BJ (2003) Changes in the surgical management of patients with breast carcinoma based on preoperative magnetic resonance imaging. Cancer 98(3):468-473

20. Fabre DN, Boulet P, Prat X, Charra L, Lesnik A, Taourel P (2005) Breast MRI in invasive lobular carcinoma: diagnosis and staging. J Radiol 86(9 Pt 1):1027-1034

21. Munot K, Dall B, Achuthan R, Parkin G, Lane S, Horgan K (2002) Role of magnetic resonance imaging in the diagnosis and single-stage surgical resection of invasive lobular carcinoma of the breast. Br J Surg 89(10):1296-1301

22. Quan ML, Sclafani L, Heerdt AS, Fey JV, Morris EA, Borgen PI (2003) Magnetic resonance imaging detects unsuspected disease in patients with invasive lobular cancer. Ann Surg Oncol 10(9):1048-1053

23. Mann RM, Hoogeveen YL, Blickman JG, Boetes C (2008) MRI compared to conventional diagnostic work-up in the detection and evaluation of invasive lobular carcinoma of the breast: a review of existing literature. Breast Cancer Res Treat 107(1):1-14

24. Jobsen JJ, Riemersma S, van der Palen J, Ong F, Jonkman A, Struikmans H (2009) The impact of margin status in breastconserving therapy for lobular carcinoma is age related. Eur $\mathbf{J}$ Surg Oncol. doi:10.1016/j.ejso.2009.06.003

25. Luini A, Rososchansky J, Gatti G, Zurrida S, Caldarella P, Viale G, Rosali dos SG, Frasson A (2009) The surgical margin status after breast-conserving surgery: discussion of an open issue. Breast Cancer Res Treat 113(2):397-402

26. Kuhl C, Kuhn W, Braun M, Schild H (2007) Pre-operative staging of breast cancer with breast MRI: one step forward, two steps back? Breast 16(Suppl 2):S34-S44

27. Morrow M, Freedman G (2006) A clinical oncology perspective on the use of breast MR. Magn Reson Imaging Clin N Am 14(3):363-378 vi

28. Morrow M (2004) Magnetic resonance imaging in breast cancer: one step forward, two steps back? JAMA 292(22):2779-2780

29. National Breast Cancer Organization Netherlands (2008) Guideline for treatment of patients with breast cancer. Kwaliteitsinstituut voor de gezondheidszorg CBO. Available via http://www.oncoline.nl

30. Morris EA (2006) Breast MR imaging lexicon updated. Magn Reson Imaging Clin N Am 14(3):293-303

31. Veltman J, Boetes C, Wobbes T, Blickman JG, Barentsz JO (2005) Magnetic resonance-guided biopsies and localizations of the breast: initial experiences using an open breast coil and compatible intervention device. Invest Radiol 40(6):379-384

32. Tresserra F, Feu J, Grases PJ, Navarro B, Alegret X, FernandezCid A (1999) Assessment of breast cancer size: sonographic and pathologic correlation. J Clin Ultrasound 27(9):485-491

33. Veltman J, Boetes C, van Die L, Bult P, Blickman JG, Barentsz JO (2006) Mammographic detection and staging of invasive lobular carcinoma. Clin Imaging 30(2):94-98

34. Watermann DO, Tempfer C, Hefler LA, Parat C, Stickeler E (2005) Ultrasound morphology of invasive lobular breast cancer is different compared with other types of breast cancer. Ultrasound Med Biol 31(2):167-174

35. Arpino G, Bardou VJ, Clark GM, Elledge RM (2004) Infiltrating lobular carcinoma of the breast: tumor characteristics and clinical outcome. Breast Cancer Res 6(3):R149-R156

36. Al-Ghazal SK, Blamey RW, Stewart J, Morgan AA (1999) The cosmetic outcome in early breast cancer treated with breast conservation. Eur J Surg Oncol 25(6):566-570

37. Wazer DE, Dipetrillo T, Schmidt-Ullrich R, Weld L, Smith TJ, Marchant DJ, Robert NJ (1992) Factors influencing cosmetic outcome and complication risk after conservative surgery and radiotherapy for early-stage breast carcinoma. J Clin Oncol 10(3):356-363

38. Pengel KE, Loo CE, Teertstra HJ, Muller SH, Wesseling J, Peterse JL, Bartelink H, Rutgers EJ, Gilhuijs KG (2009) The impact of preoperative MRI on breast-conserving surgery of invasive cancer: a comparative cohort study. Breast Cancer Res Treat 116(1):161-169

39. Aziz D, Rawlinson E, Narod SA, Sun P, Lickley HL, McCready DR, Holloway CM (2006) The role of reexcision for positive margins in optimizing local disease control after breast-conserving surgery for cancer. Breast J 12(4):331-337

40. Menes TS, Tartter PI, Bleiweiss I, Godbold JH, Estabrook A, Smith SR (2005) The consequence of multiple re-excisions to obtain clear lumpectomy margins in breast cancer patients. Ann Surg Oncol 12(11):881-885 
41. Fischer U, Zachariae O, Baum F, von Heyden D, Funke M, Liersch T (2004) The influence of preoperative MRI of the breasts on recurrence rate in patients with breast cancer. Eur Radiol 14(10):1725-1731

42. Solin LJ, Orel SG, Hwang WT, Harris EE, Schnall MD (2008) Relationship of breast magnetic resonance imaging to outcome after breast-conservation treatment with radiation for women with early-stage invasive breast carcinoma or ductal carcinoma in situ. J Clin Oncol 26(3):386-391

43. Poortmans PM, Collette L, Bartelink H, Struikmans H, Van den Bogaert WF, Fourquet A, Jager JJ, Hoogenraad W, Muller RP, Dubois JB, Bolla M, Van Der HM, Warlam-Rodenhuis CC, Pierart M, Horiot JC (2008) The addition of a boost dose on the primary tumour bed after lumpectomy in breast conserving treatment for breast cancer. A summary of the results of EORTC 22881-10882 "boost versus no boost" trial. Cancer Radiother 12(6-7):565-570
44. ACR Guidelines and Standards Committee, Basset LW, Berg WA, Birdwell RL, et al (2008) ACR practice guideline for the performance of contrast-enhanced magnetic resonance imaging (MRI) of the breast. Available via http://www.acr.org/SecondaryMain MenuCategories/quality_safety/guidelines/breast/mri_breast.aspx

45. Mann RM, Kuhl CK, Kinkel K, Boetes C (2008) Breast MRI: guidelines from the European Society of Breast Imaging. Eur Radiol 18(7):1307-1318

46. Kuhl C (2007) The current status of breast MR imaging. Part I. Choice of technique, image interpretation, diagnostic accuracy, and transfer to clinical practice. Radiology 244(2):356-378

47. Turnbull LW (2009) Dynamic contrast-enhanced MRI in the diagnosis and management of breast cancer. NMR Biomed 22(1):28-39 